J Arid Land (2013) 5(3): 268-274

doi: $10.1007 / \mathrm{s} 40333-013-0163-1$

jal.xjegi.com; www.springer.com/40333

\title{
Predicting the dynamics of local adaptation in invasive species
}

\author{
Erin K ESPELAND* \\ USDA-ARS Pest Management Research Unit, Sidney MT 59270, USA
}

\begin{abstract}
An invasive plant species may restrict its spread to only one type of habitat, or, after some time, may continue to spread into a different, often stressful, secondary, habitat. The question of whether evolution is required for an invasive species to spread from one habitat to another is currently hotly debated. In order for local adaptation to occur, genetic variation must be present within invasive populations. In this paper, I focus on the effect of habitat on the maintenance of genetic variation during the lag phase, the phase of population stability prior to expansion. Genetic diversity in invasive plant populations accumulates through multiple introductions, gene flow, mutation, and hybridization, but diversity is maintained by population level processes influencing effective population size $\left(\mathrm{N}_{\mathrm{e}}\right)$. I show that when the plastic response to the environment results in little variation in reproductive output among individuals, $\mathrm{N}_{\mathrm{e}}$ is maximized and genetic variation is maintained. Established models of plant competition show that below-ground competition reduces the variation in reproductive output, whereas competition for light increases variation in reproductive output. The same environments that maintain high $\mathrm{N}_{\mathrm{e}}$ also reduce the opportunity for selection and minimize the response to selection, and thus the effects of the environment are synchronized to prevent genetic purges. When the primary invasion habitat supports high $\mathrm{N}_{\mathrm{e}}$, conditions are ripe for local adaptation to a secondary habitat, particularly if the secondary habitat has high opportunity for selection. When the primary invasion habitat supports low $\mathrm{N}_{\mathrm{e}}$, genetic diversity is less likely to be sufficient for local adaptation to secondary habitat to occur.
\end{abstract}

Keywords: canalization; phenotypic plasticity; population expansion; secondary invasion

Citation: Erin K ESPELAND. 2013. Predicting the dynamics of local adaptation in invasive species. Journal of Arid Land, 5(3): 268-274.

No one species invades all habitats. Invasion generally begins in one habitat and may remain solely in that habitat, but in some cases, an invasive species will proliferate in one habitat and then spread to a different, secondary habitat. Although invasions are often initially quite successful in habitats where resources are high (Davis et al., 2000), spread to secondary habitat is often constrained due to low resource availability: secondary habitats are often more stressful for plant growth (Dietz and Edwards, 2006). The successful spread to a secondary habitat may be due to propagule pressure (Colautti et al., 2004; Lockwood et al., 2005), pre-adaptation (Meimberg et al., 2010), evolutionary change (Dlugosch and Parker, 2008a; Novak and Rausch, 2009), or some combination of these (Alexander et al., 2011). In addition to a species-specific ability to invade this secondary habitat, a secondary habitat may become increasingly invasible over time due to environmental changes such as legacy effects from other invasive species (Jordan et al., 2008) or increased anthropogenic disturbance such that obstacles to expansion into secondary habitat decrease over time (Pysek et al., 2011).

Plant invasion in any one habitat consists of three phases: colonization, lag, and expansion (Dietz and Edwards, 2006). Colonization is the arrival of the spe-

*Corresponding author: Erin K ESPELAND (E-mail: Erin.Espeland@ars.usda.gov) 
cies, the lag phase is where populations seem to be stable over time, and expansion is when populations rapidly expand. Expansion is the point at which invasion occurs. Because invasive species are only identified as such during or after the expansion phase, factors contributing to the transition from lag phase to expansion phase are difficult to study. Even after an invasive species has been identified in a primary habitat, invasion of secondary habitats does not occur until the expansion phase in that habitat. Thus, we also know very little about the mechanisms of secondary invasion (e.g. invasion into resource-limited habitats from resource-rich, or primary, habitats). Specifically, we do not know if the transition from lag to expansion phase requires evolutionary change in secondary habitats, and if evolutionary change is more necessary in secondary habitats compared to primary habitats (Erfmeier et al., 2011).

An increasing body of evidence indicates that evolutionary change post-introduction occurs in invasive plant species. Rapid evolution can occur, even though species often go through severe genetic bottlenecks (Dlugosch and Parker, 2008b). Evidence is also accumulating that plasticity is extremely important for the establishment and proliferation of populations of invasive plant species. Early establishment and persistence of invasive species in primary habitats is rarely determined by adaptation (Jones and Gomulkiwicz, 2012). Plasticity may be important for the initial success of invasive species (Martina and Ende, 2012; but see Monaco et al., 2005), and plasticity is also a trait that can evolve post- introduction and increase the further success of an invasion (Sultan et al., 2012). Haider et al. (2012) found that plasticity is more important than adaptation in determining the range of plant species' climatic tolerance and concomitant potential for range expansion. Epigenetic mechanisms such as DNA methylation may also contribute towards population differentiation within invasions (Richards et al., 2012). As can be seen from the recency of the above references, the question of evolutionary change as a requirement for invasion of either primary or secondary habitats is at a very early stage of being answered. We have not created a critical mass of research that we can use to determine when evolutionary change is necessary for population increase and range expansion.

Setting aside the unresolved question of how important is evolution to successful secondary invasion, we can still ask: when it is required, can we predict it? In this paper, I suggest that interactions among plasticity (the genotype by environment interaction) and invasion environments (primary and secondary) allow us to predict whether local adaptation to the secondary habitat will occur relatively quickly or relatively slowly.

\section{Specifics of the problem}

Local adaptation is a specific type of evolutionary change. The rate of evolutionary change (i.e. gene frequency change) is affected not only by the interaction of plasticity with the environment but also by the mechanics underlying the relationship between nuclear DNA and phenotypic trait transmission, including epistatic interactions, if the trait is multi-locus or single-locus, the degree of linkage disequilibrium, covariance, and rates of recombination (Lewontin and Kojima, 1960; Christiansen, 1990; Goldringer and Batallion, 2004; Hereford, 2010). However, ultimately, local adaptation rests on standing genetic variation. If there is no genotypic variation, natural selection cannot result in change in gene frequencies over time and evolution cannot occur. Whereas within-population genetic diversity accumulates through multiple introductions (Huttanus et al., 2011), hybridization (Ellstrand, 2009; Schierenbeck and Ellstrand, 2009), mutation, and gene flow, the maintenance of genetic diversity within populations depends upon effective population size, or, $\mathrm{N}_{\mathrm{e}}$. When $\mathrm{N}_{\mathrm{e}}$ is small (i.e. less than 500; Frankham, 1995), populations are more likely to lose genetic variation due to the stochastic process of genetic drift (Goldringer et al., 2001), and adaptive genetic variation is unlikely to be maintained or available for selection to act upon. Fisher's Fundamental Theorem states that gene frequency change over time will be greatest when the amount of standing genetic variation is greatest (Frank and Slatkin, 1992). $N_{e}$ is an index of this variation and describes the evolutionary potential of a population (Willi et al., 2006; Willi and Hoffman, 2009). $\mathrm{N}_{\mathrm{e}}$ can be robust to 
fine-scale effects such as population subdivision and multi- vs single-locus traits (Siol et al., 2007) and has been shown to be correlated with both higher fitness (Reed, 2005) and higher degrees of local adaptation (Leimu and Fischer, 2008).

$\mathrm{N}_{\mathrm{e}}$ is usually expressed as the ratio $\mathrm{N}_{\mathrm{e}} / \mathrm{N}$, where $\mathrm{N}$ is the census size of the population (i.e. the number of individuals). $\mathrm{N}_{\mathrm{e}} / \mathrm{N}$ can be estimated in several ways in plant populations: by estimating the amount of inbreeding $\left(\mathrm{N}_{\mathrm{el}}\right.$; Hartl and Clark, 2007), by determining variance in reproduction $\left(\mathrm{N}_{\mathrm{eV}}\right.$; Hedrick, 2005), and, in the case of annual plants, by compiling the variation in the census population size across years $\left(\mathrm{N}_{e K}\right.$; Kalinowski and Waples, 2002). Variance in reproduction is particularly important: it can be measured in the field, the environment has a profound effect on reproductive hierarchies within populations (van Kleunen et al., 2001, 2005), and variance in reproductive success is often the primary determinant of $\mathrm{N}_{\mathrm{e}} / \mathrm{N}$ (Nunney, 1995; Siol et al., 2007). Because the environment contributes to variance in reproductive success and thus determines $\mathrm{N}_{\mathrm{e}} / \mathrm{N}$, the environment plays a critical role in the maintenance of genetic diversity within plant populations (Espeland and Rice, 2010).

\section{Modeling the problem}

\subsection{Modeling $\mathrm{N}_{\mathrm{eV}}$ and $\mathrm{N}_{\mathrm{eI}}$}

In order to compare environmental influences on $\mathrm{N}_{\mathrm{eV}}$ and $\mathrm{N}_{\mathrm{el}}$, we must first make an assumption about population growth, or change in $\mathrm{N}$ across generations. When evolution is important in biological invasions, the presumption is that evolution is required for population expansion (Dietz and Edwards, 2006). For this reason, and for simplicity, I consider the accumulation of genetic variation with no explosive population growth, setting $\mathrm{N}_{\mathrm{t}-1}=\mathrm{N}$ (no population growth) and the mean reproductive output per plant $(\mu)$ equal to one. I assume random mating $(\sigma=0)$ and assume a population of annual plants that are capable of self-fertilization and with no seed bank. The variance in reproductive output among $\mathrm{k}$ individuals is represented by either $\mathrm{S}_{\mathrm{k}}{ }^{2}$ (Gaussian-corrected) or $\sigma_{\mathrm{k}}{ }^{2}$. The appropriate $\mathrm{N}_{\mathrm{eV}}$ equation is Eq. 1 from Crow and Denniston (1988):

$$
\frac{1}{N_{e V}}=\frac{1-\alpha+\frac{(1+\alpha) S_{k}^{2}}{\mu_{k}}}{2 N_{t}} .
$$

If we compare this equation to the appropriate $\mathrm{N}_{\mathrm{eI}}$ equation from the same paper (Crow and Denniston, 1988)

$$
\frac{1}{N_{e I}}=\frac{\mu_{k}-1+\frac{\sigma_{k}^{2}}{\mu_{k}}}{N_{t-1} \times \mu_{k}-1} .
$$

We see that in both cases, the relationship between the variance in reproductive output (and the mean of reproductive output $(\mu \downarrow k))$ is critical in determining both $\mathrm{N}_{\mathrm{eI}}$ and $\mathrm{N}_{\mathrm{eV}}$. Although Crow and Denniston (1988) state that $\mathrm{N}_{\mathrm{eV}}$ is more important when interested in conserving genetic variance and allele frequency change, $\mathrm{N}_{\mathrm{eI}}$ is more useful if examining gene identity and evolution of particular genes. Because $\mathrm{N}_{\mathrm{eV}}$ is highly dependent on the number of progeny but $\mathrm{N}_{\mathrm{eI}}$ is highly dependent on the number of parents, expanding populations have higher $\mathrm{N}_{\mathrm{eV}}$ relative to $\mathrm{N}_{\mathrm{eI}}$ compared to the $\mathrm{N}_{\mathrm{eV}}: \mathrm{N}_{\mathrm{eI}}$ ratio in stable populations. However, the fact that both indices are negatively correlated with variance in reproductive output relative to the mean indicates that ecological factors that determine the variance:mean ratio of reproductive outputs are critical to maintain genetic variation regardless of the $\mathrm{N}_{\mathrm{e}}$ index used.

A well-modeled interaction between plant populations and their environment that determines the variance:mean ratio of reproductive outputs is that of competitive symmetry. When competition is asymmetrical, such as when the contested resource is for light (Weiner and Thomas, 1986), larger plants shade smaller ones, reducing their growth (Fig. 1a; plant growth schematic on left side). Thus, smaller plants are not able to gain resources proportionate to their relative size at the start of the growing season. By the end of the growing season, asymmetrical competition results in a large variance in plant sizes. Furthermore, the effects of competition are greater as plant densities increase. Thus, as shown in the graph on the right side of Fig. 1a, even if average plant size $(\mu)$ remains constant as plant densities increase, the variance in plant size $\left(\sigma^{2}\right)$ will increase as light becomes more and more 


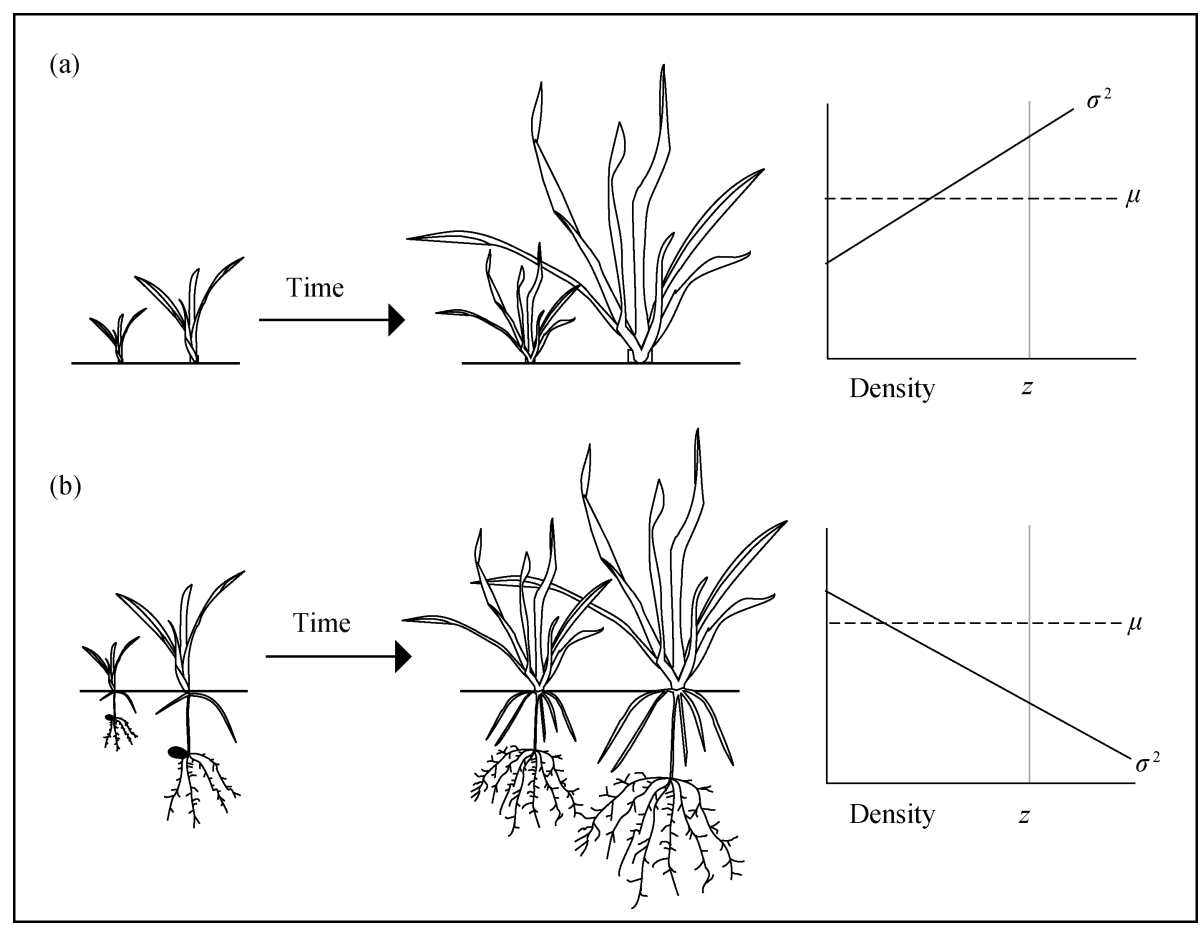

Fig. 1 Dynamics of plant-plant interactions affect variance:mean of reproductive outputs: (a) above-ground competition, (b) below-ground competition. $\sigma^{2}$ indicates variance, $\mu$ indicates mean.

contested. When below-ground competition occurs among plants, each plant is able to gain resources in proportion to its size, resulting in relatively less variance in plant size at the end of the growing season (Fig. 1b left side; Schwinning, 1996). Again, as plant density increases, the effect of competition is stronger, and variance decreases with increasing density (Fig. lb right side). Size is often highly correlated with reproductive output (Wilson and Levin, 1986); in effect, size hierarchies in annual plants are functionally reproductive hierarchies. Thus, consider the case where two population patches are the same in size and density $(\mathrm{N})$ and no population growth occurs (i.e. $\mathrm{N}_{\mathrm{t}-\mathrm{l}}=\mathrm{N}_{\mathrm{t}}$ ), but one has a relatively uniform size distribution (e.g. competition in edaphically-stressful environments) and the other has a highly skewed size distribution (e.g. light is contested). This scenario is shown by the gray lines at equal densities $(Z)$ in Figs. 1a and b. In this case, the mean reproductive output per plant is the same between the two patches, but the patch where belowground resources are contested will maintain higher amounts of genetic variation due to the lower variance in plant size and thus in reproductive output.

\subsection{Modeling the opportunity for and response to selection}

In addition to environmental impacts on $\mathrm{N}_{\mathrm{e}}$ by determining variance:mean scaling in reproductive outputs, environment also affects the opportunity for selection within populations. Clearly for natural selection to act, not only must there be genetic variation to act upon, but that variation must be phenotypically expressed. If two genotypes have exactly the same fitness, natural selection cannot distinguish between the two genotypes. The opportunity for selection, $I$, is determined by the degree of phenotypic variance in a population. $I$ is equal to variance in relative fitness within a population (Crow, 1989), thus $I$ is also dependent on the scaling of variance:mean in reproductive outputs. As shown in the competitive symmetry example, the environment can constrain phenotypic differentiation by reducing the amount of variation among individuals. When the environment reduces variation among individuals, it increases $\mathrm{N}_{\mathrm{e}}$ and decreases $I$.

Plasticity, or the genotype by phenotype interaction, allows the environment to play a significant role in the determination of $\mathrm{N}_{\mathrm{e}}$ and also allows the environment to affect $I$. Plasticity not only allows environmental 
determination of $\mathrm{N}_{\mathrm{e}}$ and $I$, it also affects the response to selection (R), which is the square root of $I$ (Arnold and Wade, 1984). The response to selection is the change in phenotypic mean across generations due to a selective force. $\mathrm{R}$ places a limit on the amount by which a phenotypic mean can be shifted in response to a selective agent.

Plasticity within plant populations has implications for heritability $(\mathrm{H})$, another factor directly related to the response to selection. When a trait is plastic, the $\mathrm{H}$ value for that trait is reduced. Although reproductive hierarchies normally found in plant populations greatly increase the rate of genetic drift compared to neutral assumptions of reproductive distributions, surprisingly this relationship is not greatly altered by different $\mathrm{H}$ values (Wilson and Levin, 1986).

\subsection{Model summary}

Local adaptation requires standing genetic variation $\left(\mathrm{N}_{\mathrm{e}}\right)$, opportunity for selection $(I)$, response to selection $(\mathrm{R})$, and trait heritability $(\mathrm{H})$. The first three are affected in parallel by the environment: as the environment reduces variation relative to the mean, it increases $\mathrm{N}_{\mathrm{e}}$ and decreases $I$ and $\mathrm{R}$, which allows genetic variation to continue to accumulate and not be purged by natural selection. When we examine populations in the lag phase, if they are located in habitats that reduce variation:mean, these populations will maintain genetic diversity more effectively than populations in habitats that increase variation:mean. Populations located in habitats that increase variation:mean will lose genetic variation to drift. In fact, Lynch and colleagues (1995) show that $\mathrm{N}_{\mathrm{e}}<100$ and $\mathrm{N}$ less than 1,000 leads to mutational meltdown (i.e. accumulation of deleterious mutations) and extinction of small populations within 100 generations. Thus, in order for a lag phase to progress not only to persistence but to expansion (i.e. invasion), $\mathrm{N}_{\mathrm{e}}$ of the colonizing species must be greater than 100 and must move past that number in relatively few generations. If local adaptation is required for expansion in secondary habitat, primary habitats that reduce variation:mean will house populations that are more likely to have the requisite standing genetic variation for that local adaptation to take place. Likewise, with number of migrants and $\mathrm{N}$ being equal, primary habitats with more stochasticity and greater variation:mean in reproductive outputs will be less likely to maintain genotypes required for local adaptation to secondary habitat.

\section{Implications}

In some cases, local adaptation may be necessary for a plant species to successfully invade (i.e. move from the lag phase to the expansion phase) a new habitat. Some amount of genetic variation is critical in order for local adaptation to occur. Although multiple introductions and the high migration rate associated with invasive species are dominant contributors to increased genetic variation, the environment also plays a role in maintaining genetic variation. In addition, the spatial arrangement of primary and secondary habitat invasion is key: where is genetic variation accumulating and where is natural selection occurring?

Standing genetic variation must be both generated and maintained in order to provide an opportunity for selection and potential for local adaptation. Plasticity (the genotype by environment interaction) determines the ability of a population to maintain accumulated genetic variation: low variation in fitness in the primary invasion environment promotes greater evolutionary potential and may speed the process of adaptation to secondary invasion environments. High variation in fitness within the primary invasion environment may lead to lower standing genetic variation and thus slow the rate of adaptation to secondary invasion environments.

In addition to the maintenance of standing genetic variation, landscape-level and historic effects also determine the likelihood of secondary invasion. Secondary habitat located near a primary habitat that promotes high $\mathrm{N}_{\mathrm{e}}$ may be more likely to be invaded than a secondary habitat that is more distant from a primary habitat. In addition, the steepness of the environmental gradient between primary and secondary habitats matters: secondary invasion and adaptation are more likely when the gradient is shallow (Hufbauer et al., 2012). The "familiarity" of the gradient may also indicate the capacity of a species to local adaptation (Dlugosch and Parker, 2008a): if the species has successfully adapted to a certain habitat in its native 
range, it is more likely to have the capacity to adapt to that habitat in its introduced range.

The hypothetical relationship between field measures of reproductive variance to the capacity of populations to local adaptation has not been tested and supported (Espeland and Rice, 2010). The relationship between variance:mean in reproductive output and local adaptation has the potential to be a fruitful area of invasive species research because management and control activities can also affect the adaptive capacity of invasive plant species (Leger and Espeland, 2010). An evolutionary perspective can be useful in targeting the approach to invasive species management: we not only need to prevent the spread of invasive species, we also need to frustrate the capacity for local adaptation (Novak and Rausch, 2009). Targeting populations that harbor and maintain the greatest genetic diversity for management, and preventing populations of invasive plant species from becoming more genetically diverse by discontinuing both reintroduction and assisted migration, will reduce the likelihood of invasions that are dependent on local adaptation for their success.

\section{Acknowledgements}

I would like to thank Kevin RICE for many conversations that resulted in the development of this theoretical framework. Two anonymous reviewers, R NOWAK, J GASKIN, K KETTENRING, and T RAND provided helpful comments on the manuscript. Thanks to B REDLIN for graphic design and to the organizers and supporters of the International Symposium on Invasive Plants and Global Change in Urumqi, China in 2012 for their commendable work in building a successful meeting.

\section{References}

Alexander J M, Kueffer C, Daehler C C, et al. 2011. Assembly of nonnative floras along elevational gradients explained by directional ecological filtering. Proceedings of the National Academy of Sciences, 108(2): 656-661.

Arnold S J, Wade M J. 1984. On the measurement of natural and sexual selection: theory. Evolution, 38(4): 709-719.

Christiansen F B. 1990. Simplified models for viability selection at multiple loci. Theoretical Population Biology, 37: 39-54.

Colautti R I, Ricciardi A, Grigorovich I A, et al. 2004. Is invasion success explained by the enemy release hypothesis? Ecology Letters, 7: $721-733$

Crow J F, Denniston C. 1988. Inbreeding and variance effective popu- lation numbers. Evolution, 42(3): 482-495.

Crow J F. 1989. Fitness variation in natural populations. In: Hill W G, Mackay T F C. Evolution and Animal Breeding: Reviews on Molecular and Quantitative Approaches in Honor of Alan Robertson, Wallingford: CAB International, 91-97.

Davis M A, Grime P J, Thompson K. 2000. Fluctuating resources in plant communities: a general theory of invisibility. Journal of Ecology, 88(3): 528-534.

Dietz H, Edwards P J. 2006. Recognition that causal processes change during plant invasion helps explain conflicts in evidence. Ecology, 87(6): 1359-1367.

Dlugosch K M, Parker I M. 2008a. Founding events in species invasions: genetic variation, adaptive evolution, and the role of multiple introductions. Molecular Ecology, 17: 431-449.

Dlugosch K M, Parker I M. 2008b. Invading populations of an ornamental shrub show rapid life history evolution despite genetic bottlenecks. Ecology Letters, 11: 701-709.

Ellstrand N C. 2009. Evolution of invasiveness in plants following hybridization. Biological Invasions, 11: 1089-1091.

Erfmeier A, Bohnke M, Bruelheide H. 2011. Secondary invasion of Acer negundo: the role of phenotypic responses versus local adaptation. Biological Invasions, 13: 1599-1614.

Espeland E K, Rice K J. 2010. Ecological effects on estimates of effective population size in an annual plant. Biological Conservation, 143: 946-951.

Frank S A, Slatkin M. 1992. Fisher's fundamental theorem of natural selection. Trends in Ecology and Evolution, 7(3): 92-95.

Frankham R. 1995. Effective population size/adult population size ratios in wildlife: a review. Genetics Research, 66: 95-107.

Goldringer I, Enjalbert J, Raquin A L, et al. 2001. Strong selection in wheat populations during ten generations of dynamic management. Genetics Selection Evolution, 33(S1): 441-463.

Goldringer I, Bataillon T. 2004. On the distribution of temporal variations in allele frequency: consequences for the estimation of effective population size and detection of loci undergoing selection. Genetics, 168: 563-568.

Haider S, Kueffer C, Edwards P J, et al. 2012. Genetically based differentiation in growth of multiple non-native plant species along a steep environmental gradient. Population Ecology, 170: 89-99.

Hartl D L, Clark A G. 2007. Principles of Population Genetics. Sunderland: Sinauer Associates.

Hedrick P. 2005. Large variance in reproductive success and the $\mathrm{Ne} / \mathrm{N}$ ratio. Evolution, 59(7): 1596-1599.

Hereford J. 2010. Does selfing or outcrossing promote local adaptation? American Journal of Botany, 97(2): 298-302.

Hufbauer R A, Facon B, Ravigne V, et al. 2012. Anthropogenically induced adaptation to invade (AIAI): contemporary adaptation to human-altered habitats within the native range can promote invasions. Evolutionary Applications, doi: 10.1111/j.1752-4571.2011. 00211.x. 
Huttanus T D, Mack R N, Novak S J. 2011. Propagule pressure and introduction pathways of Bromus tectorum (cheatgrass; Poaceae) in the central United States. International Journal of Plant Sciences, 172(6): 783-794.

Jones E I, Gomulkiewicz R. 2012. Biotic interactions, rapid evolution, and the establishment of introduced species. The American Naturalist, $179(2)$ : 28-36.

Jordan N R, Larson D L, Huerd S C. 2008. Soil modification by invasive plants: effects on native and invasive species of mixed-grass prairies. Biological Invasions, 10: 177-190.

Kalinowski S T, Waples R S. 2002. Relationship of effective to census size in fluctuating populations. Conservation Biology, 16(1): 129-136.

Leger E A, Espeland E K. 2010. Coevolution between native and invasive plant competitors: implications for invasive species management. Evolutionary Applications, 3: 169-178.

Leimu R, Fischer M. 2008. A meta-analysis of local adaptation in plants. PLoS One, 3(12): e4010.

Lewontin R C, Kojima K. 1960. The evolutionary dynamics of complex polymorphisms. Evolution, 14(4): 458-472.

Lockwood J L, Cassey P, Blackburn T. 2005. The role of propagule pressure in explaining species invasions. Trends in Ecology and Evolution, 20: 223-228.

Lynch M, Conery J, Burger R. 1995. Mutation accumulation and the extinction of small populations. The American Naturalist, 146(4): 489-518.

Martina J P, von Ende C N. 2012. Highly plastic response in morphological and physiological traits to light, soil-N and moisture in the model invasive plant, Phalaris arundinacea. Environmental and Experimental Botany, 82: 43-53.

Meimberg H, Milan N F, Karatassiou M, et al. 2010. Patterns of introduction and adaptation during the invasion of Aegilops triuncialis (Poaceae) into Californian serpentine soils. Molecular Ecology, 19: 5308-5319.

Monaco T A, Johnson D A, Creech J E. 2005. Morphological and physiological responses of the invasive weed Isatis tinctoria to contrasting light, soil-nitrogen and water. Weed Research, 45: 460-466.

Novak S J, Rausch J H. 2009. Use of field surveys, distributional data and genetic analyses to monitor alien species: Taeniatherum caput-medusae as an example of the approach. Neobiota, 8: 169-182.

Nunney L. 1995. Measuring the ratio of effective population size to adult numbers using genetic and ecological data. Evolution, 49(2): 389-392

Pysek P, Vojtech J, Pergl J, et al. 2011. Colonization of high altitudes by alien plants over the last two centuries. Proceedings of the National Academy of Sciences, 108(2): 439-440.

Reed D H. 2005. Relationship between population size and fitness. Conservation Biology, 19: 563-568.

Richards C L, Schrey A W, Pigliucci M. 2012. Invasion of diverse habitats by few Japanese knotweed genotypes is correlated with epigenetic differentiation. Ecology Letters, 15: 1016-1025.

Schierenbeck K A, Ellstrand N C. 2009. Hybridization and the evolution of invasiveness in plants and other organisms. Biological Invasions, 11: 1093-1105.

Schwinning S. 1996. Decomposition analysis of competitive symmetry and size structure dynamics. Annals of Botany, 77: 47-57.

Siol M, Bonnin I, Oliveri I, et al. 2007. Effective population size associated with self-fertilization: lessons from temporal changes in allele frequencies in the selfing annual Medicago trunculata. Journal of Evolutionary Biology, 20: 2349-2360.

Sultan S E, Horgan-Kobelski T, Nichols L M, et al. 2012. A resurrection study reveals rapid adaptive evolution within populations of an invasive plant. Evolutionary Applications, doi:10.1111/j.1752-4571. 2012.00287.x.

Van Kleunen M, Fischer M, Schmid B. 2001. Effects of intraspecific competition on size variation and reproductive allocation in a clonal plant. Oikos, 94: 515-524.

Van Kleunen M, Fischer M, Schmid B. 2005. Three generations under low versus high neighborhood density affect the life history of a clonal plant through differential selection and genetic drift. Oikos, 108: 573-581.

Weiner, J, Thomas S C. 1986. Size variability and competition in plant monocultures. Oikos, 47: 211-222.

Willi Y, van Buskirk J, Hoffmann A A. 2006. Limits to the adaptive potential of small populations. Annual Review of Ecology Evolution and Systematics, 37: 433-458.

Willi Y, Hoffmann A A. 2009. Demographic factors and genetic variation influence population persistence under environmental change. Journal of Evolutionary Biology, 22: 124-133.

Wilson J B, Levin D A. 1986. Some genetic consequences of skewed fecundity distributions in plants. Theoretical and Applied Genetics, 73: 113-121. 